\title{
$\underline{\text { Reactor Design With Matlab In a Manufacturing Environment }}$
}

\author{
Dr. Charles U. Okonkwo \\ Arizona State University
}

\begin{abstract}
The motivation for this study arises from a class project in an Alternative Energy course MET 494. A professor with mechanical processing background taught the course to students with similar background during the 1996 fall semester. During the 1996 spring semester, the professor's MET 494 students produced hydrogen in a batch reactor via a methane steam reforming reaction on a nickel catalyst. The batch reactor temperature was about $800{ }^{\circ} \mathrm{C}$ and pressures varied between 85 and 97 psig. The class objective, among other things, was to produce hydrogen in a continuous flow reactor and understand the behavior of such a reactor.

Hydrogen is a promising fuel alternative. As an additive, hydrogen may boost the performance of jet propulsion engines. Some auto manufacturers have begun research in this area. For example, Mazda has already produced a hydrogen fueled prototype engine that outperformed electric prototype engines. Diamler-Benz is also researching the use of hydrogen in internal combustion engines. Additionally, the students' future objective is to research the use of hydrogen as a stand alone alternative in jet propulsion and internal combustion engines. The professor asked me to help design a reactor, which the students would build.

I have modeled hydrogen production using a packed bed reactor. The design equations consist of coupled material and energy balances. Rate kinetics used in the design equations were obtained from the literature. The design equations contain one endothermic reaction and one exothermic reaction, yielding an overall reaction that is endothermic. I used Matlab to solve the resulting five nonlinear ordinary differential equations and an algebraic equation. Using the model the students can simulate production of hydrogen by adjusting reactor length, area, heating of reactants, molar flow rates of methane and steam, inlet temperature, inlet pressure and obtain hydrogen yield and flow rates of by-products. It uses a non temperature dependent rate constant obtained from the literature, and can be modified to handle a temperature dependent rate constant. The model gives a decreasing temperature profile across reactor length. The model can handle pressure calculations by simply adding an extra differential equation involving pressure as a dependent variable. However, it assumes constant pressure due to cost considerations. The model empowers the student to build and study the methane steam reforming reactor and gain better insight.
\end{abstract}




\section{Introduction}

The promise of hydrogen as a fuel for automobile and jet propulsion engine has sparked interest in hydrogen production. This opinion is shared by Marr (1). Steam methane reforming (SMR) is the method of hydrogen production described in this study.

According to Rosen and Scott (2), it is one of the most important industrial processes for hydrogen production today. Rosen and Scott (1) describe the status of SMR process to be a mature technology. Though the process involves both exothermic and endothermic reactions, the net reaction is endothermic. The energy required to promote the reaction is supplied by heat from the exhaust of an automobile engine and a built-in heater inside the reactor that can be turned off and on. The MET 494 students have background in metal working based manufacturing. I undertook the modeling to enhance the students' knowledge regarding the behavior of the reactor, at least in a qualitative manner. The model allows the simulation of the reactor via parameters such as cross-sectional area of reactor, molar flow rates of reaction components, built-in heating, q inside the reactor, inlet temperature of reactants and reactor length. Due to unforeseen circumstances, the students completed building the reactor at the end of the semester and had no time to run the experiment. I have simulated hydrogen production on the computer using matlab. This should prove to be a valuable tool in running the hydrogen production experiment.

\section{Reactions Within the Packed Bed Reactor/Theory Behind the Packed bed Reactor}

The two reactions involved in the reforming of natural gas over a nickel catalyst are given below:

$$
\begin{aligned}
\mathrm{CH}_{4}+\mathrm{H}_{2} \mathrm{O} \rightarrow & \mathrm{CO}+3 \mathrm{H}_{2} \\
& \Delta \text { Hrxn }=+206 \mathrm{~kJ} \mathrm{~mol}^{-1} \\
\mathrm{CO}+\mathrm{H}_{2} \mathrm{O} \Leftrightarrow & \mathrm{CO}_{2}+\mathrm{H}_{2}
\end{aligned}
$$

$$
\Delta H r x n=-41 \mathrm{~kJ} \mathrm{~mol}^{-1}
$$

The reforming reaction, equation (1) is highly endothermic, while the water gas shift reaction, equation (2) is exothermic. The overall reaction is endothermic. The reforming reaction is far from equilibrium, whereas the shift reaction is very close to equilibrium. Agnelli et al. (3).

\section{Theory Behind the Packed bed Reactor Modeling Equations for Packed Bed Reactor}

Table 1 , a listing of reactor variables and their respective units, facilitates readability of the model equations. 


\section{$\underline{\text { Table } 1}$}

$\underline{\text { Variable }}$

A Methane

B Water

C Carbon Monoxide

D Hydrogen

E Carbon Dioxide

T Temperature

S Cross sectional area of reactor

$\mathrm{C}_{\mathrm{pi}} \quad$ Specific heat of component $\mathrm{i}$

$r_{\mathrm{A}} \quad$ Reaction rate expression

$\rho_{b} \quad$ Catalyst bulk density

q Heating inside reactor

k Reaction rate constant

$\mathrm{P}_{\mathrm{i}} \quad$ Partial pressure of component $\mathrm{i}$

$\mathrm{P}_{\mathrm{T}} \quad$ Total pressure

$\mathrm{n}_{\mathrm{i}} \quad$ Molar flow rate component $\mathrm{i}$

$\mathrm{n}_{\mathrm{T}} \quad$ Total molar flow rate

$\mathrm{K}(\mathrm{T})$ Equilibrium constant

$\mathrm{K}_{\mathrm{A}} \quad$ Constant taken from Agnelli's data

$\mathrm{K}_{\mathrm{B}} \quad$ Constant taken from Agnelli’s data

z Reactor length

\section{$\underline{\text { Units }}$}

none

none

none

none

none

kelvin

$(\text { meter })^{2}$

joule/(g mole $\bullet$ kelvin $)$

$\mathrm{g}$ mole/ (volume of catalyst $\bullet$ minute)

gram catalyst/ volume of catalyst

joule/(minute $\bullet$ meter $)$

g mole/(gram catalyst $\bullet$ minute $\bullet$ atmosphere $)$

atmospheres

atmospheres

g mole/ min

$\mathrm{g}$ mole/ min

none

none

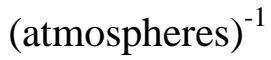

meters 
Assuming steady state, the requisite equations for the model are given below:

$\frac{d n_{A}}{d z}=-S r_{A}, \quad n_{A}(0)=n_{A 0}$

$\frac{d n_{B}}{d z}=-S r_{A}, \quad n_{B}(0)=n_{B 0}$

$\frac{d n_{C}}{d z}=S r_{A} \quad, \quad n_{C}(0)=n_{C 0}$

$\frac{d n_{D}}{d z}=3 S r_{A}, \quad n_{D}(0)=n_{D 0}$

$\frac{d T}{d z}=\frac{-S\left(\Delta H_{r x n}\right) r_{A}}{n_{A} c_{P A}+n_{B} c_{P B}+n_{C} c_{P C}+n_{D} c_{P D}}+\frac{q}{n_{A} c_{P A}+n_{B} c_{P B}+n_{C} c_{P C}+n_{D} c_{P D}} \quad, \mathrm{~T}(\mathrm{z}=0)=\mathrm{T}_{0}$

$K(T)=\frac{n_{E} n_{D}}{n_{C} n_{B}}$

where the reaction rate, $r_{A}$ is given by:

$$
\begin{aligned}
r_{A}= & \frac{k P_{A} \rho_{b}}{\left(1+K_{A} \frac{P_{B}}{P_{D}}+K_{B} P_{C}\right)^{n}}, \text { where } P_{i}=\frac{n_{i} P_{T}}{n_{T}} \text {, and subscript } " i "=A, B, C \text { or } D \\
r_{A}= & \frac{k P_{T} \frac{n_{A}}{n_{T}} \rho_{b}}{\left(1+K_{A} \frac{n_{B}}{n_{D}}+K_{B} P_{T} \frac{n_{C}}{n_{T}}\right)^{n}} \text {, where } P_{T} \text { is total pressure }
\end{aligned}
$$

In general, $\mathrm{k}$ is a function of T. Agnelli et al. (3) lists three values of $\mathrm{k}, \mathrm{K}_{\mathrm{A}}, \mathrm{K}_{\mathrm{B}}$ at different temperatures for different reaction rate models, and different power, $\mathrm{n}$ values. This suggests that a regression technique can be used to write $\mathrm{k}, \mathrm{K}_{\mathrm{A}}, \mathrm{K}_{\mathrm{B}}$, each as a function of T. Since we are more interested in the qualitative behavior of the reactor, a first level approximation using constant values of $\mathrm{k}, \mathrm{K}_{\mathrm{A}}, \mathrm{K}_{\mathrm{B}}$ is sufficient. Agnelli et al. (3) indicates that the above reaction rate expression with power, $n=1$ is adequate for describing hydrogen production via methane steam reforming. Matlab is the application package used in solving the above model equations 3 through 10 for different combinations of reactor parameters. I have shown below an example Matlab program for certain combinations of reactor parameters. 


\section{Matlab Program}

global PT S DELH Q CPA CPB CPC CPD NA NC NB ND NE NT

$\mathrm{PT}=1.5 ; \% \mathrm{PT}$ is total pressure in atmospheres

$\mathrm{S}=0.05 ; \% \mathrm{~S}=0.5$ square meters of area

$\mathrm{DELH}=206014$; \% DELH is heat of reaction in Joules per gram mole

$\mathrm{Q}=5000 ; \%$ Heat input rate per unit lenth of bed (Joules/min-meter)

$\mathrm{CPA}=36.9607 ; \%$ specific heat $(\mathrm{J} /$ gmole-K$)$

$\mathrm{CPB}=33.7295 ; \%$ specific heat $(\mathrm{J} /$ gmole-K $)$

$\mathrm{CPC}=29.1668 ; \%$ specific heat $(\mathrm{J} / \mathrm{gmole}-\mathrm{K})$

$\mathrm{CPD}=28.6455 ; \%$ specific heat $(\mathrm{J} /$ gmole-K$)$

$\mathrm{zzO}=0.0 ;$

$\mathrm{zzf}=0.5$

YY0 = $[3 ; 3.5 ; 0 ; 0.000001 ; 1300] ;$

[zz,YY] = ode23('chrlspr3',zz0,zzf,YY0);

$\mathrm{K}=0.45$; \% For now, $\mathrm{K}$ is assumed to be independent of temperature, $\mathrm{K}=$ constant

$\mathrm{NA}=\mathrm{YY}(:, 1)$

$\mathrm{NB}=\mathrm{YY}(:, 2)$;

$\mathrm{NC}=\mathrm{YY}(:, 3)$;

$\mathrm{ND}=\mathrm{YY}(:, 4)$;

$\mathrm{T}=\mathrm{YY}(:, 5)$;

$\mathrm{NE}=.45^{*} \mathrm{YY}(:, 3){ }^{*} \mathrm{YY}(:, 2) . / \mathrm{YY}(:, 4)$;

$\mathrm{NT}=\mathrm{NA}+\mathrm{NB}+\mathrm{NC}+\mathrm{ND}+\mathrm{NE}$;

plot(zz,NA,'r+',zz,NB,'g-')

title('MOLES/MIN versus REACTOR LENGTH')

xlabel(' Reactor Length')

ylabel('Gram-moles/min')

grid

pause, close

plot(zz,NC,'b-.',zz,ND,'y--',zz,NE,'r+')

title('MOLES/MIN versus REACTOR LENGTH')

xlabel(' Reactor Length')

ylabel('Gram-moles/min')

grid

pause, close

$\operatorname{plot}(\mathrm{zz}, \mathrm{T})$

title('TEMPERATURE versus REACTOR LENGTH')

xlabel('Reactor Length')

ylabel('TEMPERATUTE ${ }^{0} \mathrm{~K}$ ')

grid

function $\mathrm{W}=\operatorname{chrlspr} 3(\mathrm{zz}, \mathrm{YY})$ 


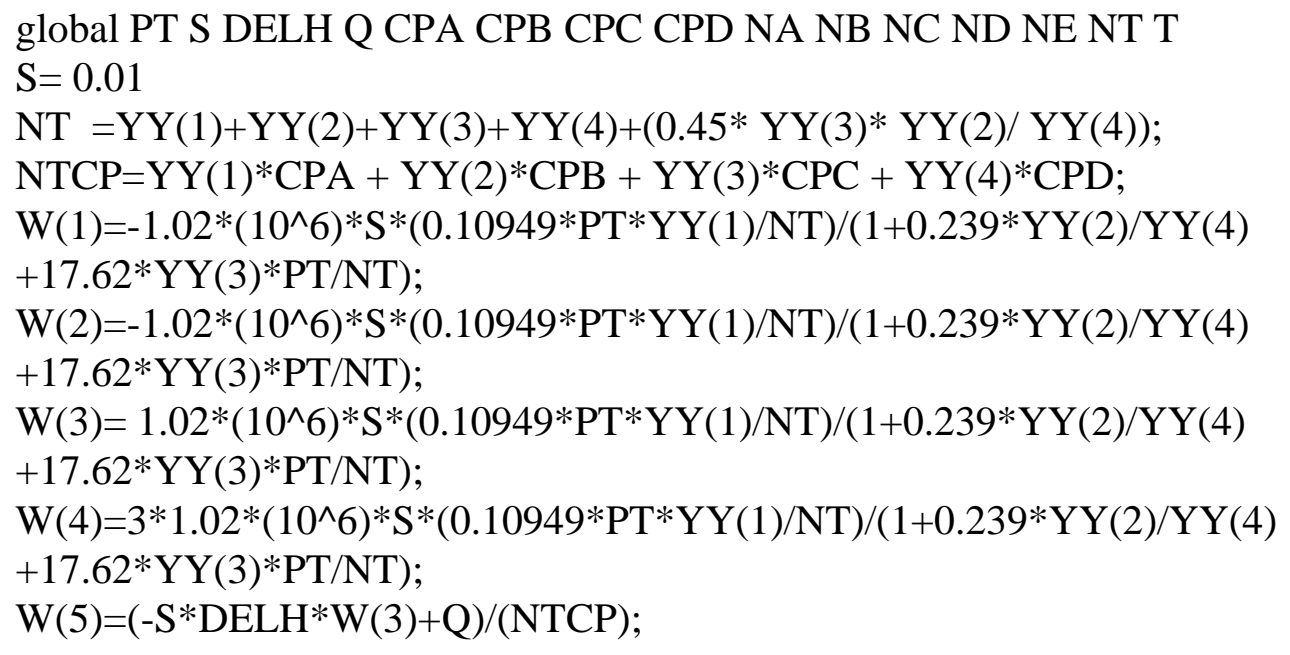

\section{Results and Discussion}

A constant value of 0.45 has been used for the equilibrium constant $K(T)$. A low value of $\mathrm{K}$ is required, because the shift reaction, equation (2) is an equilibrium reaction. Twigg (4) lists equilibrium constants at various temperatures in appendix 7 of his book. Also, a constant value of $\Delta H_{\text {rxn }}$ is used in this first level approximation. The bulk density of nickel catalyst , $\rho_{b}$, used in this simulation is $1.02 * 10^{6}$ gram catalyst/( meter $\left.^{3}\right)$. In order to prevent division by zero during the first iteration steps in Matlab, the initial condition on hydrogen molar flow rate, $\mathrm{n}_{\mathrm{D} 0}$ is set to 0.000001 . An example set of parameters is shown below:

\begin{tabular}{llrlllllll} 
& \multicolumn{10}{c}{$\mathbf{P}_{\mathbf{T}}=1$ atmosphere } \\
$\mathrm{S}$ & $\Delta H_{\mathrm{rxn}}$ & ratio & $\mathrm{q}$ & $\mathrm{k}$ & $\mathrm{K}$ & $\mathrm{K}_{\mathrm{A}}$ & $\mathrm{K}_{\mathrm{B} Z}$ & $\mathrm{~T}_{0}$ & \\
0.01 & 206014 & $3.5 / 3$ & 5,000 & 0.10949 & 0.45 & 0.239 & 17.62 & 0.5 & 1300 \\
0.01 & 206014 & $13.5 / 3$ & 5,000 & 0.10949 & 0.45 & 0.239 & 17.62 & 0.5 & 1300 \\
0.01 & 206014 & $3.5 / 3$ & 50,000 & 0.10949 & 0.45 & 0.239 & 17.62 & 0.5 & 1300
\end{tabular}

Figures 1 through 3 depict the graphs resulting from the simulation of the first combination of parameters, figures 4 and 5 show those from the second combination of parameters, and figure 6 show those resulting from the third combination of parameters. It is obvious that the number of possible combinations is very large. Therefore, in order to understand the behavior of the reactor, it suffices to show graphs of a few of the simulations.

All plots show that a reactor with a cross-sectional area of 0.01 (meters) $^{2}$ and a length between 0.25 and 0.3 meters will yield almost complete conversion for the given feed (water/methane) ratio. Figures 3 and 5 indicate that for the case of moderate heating, $\mathrm{q}=5,000$ joules/(meter $\bullet$ minute), the reactor temperature does not rise above the inlet feed temperature. This suggests that most of the heat from the heater is used in promoting the endothermic reaction. For very high heating, $q=50,000$ joules $/($ meter $\bullet$ minute), figure 6 indicates that the temperature is rising. For much larger q values, not displayed, the 
reactor temperature actually rises above the feed temperature without any appreciable change in conversion. This suggests that excess heat is used to raise the reactor temperature. Figures 2 and 4 indicate that a high molar ratio (13.5/3) of water to methane promotes the formation of carbon dioxide in the shift reaction. Therefore, the rate of hydrogen formation is slower for the case of high molar ratio. This suggests that an optimal ratio, which gives the best performance, exists. In practice, we would find this ratio experimentally.

\section{Conclusion}

The model is capable of simulating various combinations of reactor parameters. As a first approximation model, it is useful for designing a steam methane reactor for the production of hydrogen. It provides reactor size for certain feed rates. A more accurate model may be obtained by inputting $\mathrm{k}, \mathrm{K}, \Delta H_{\mathrm{rxn}}$ as functions of temperature into the Matlab program.

\section{References}

(1) Marr, A. 1996. Hydrogen Powered Rotaries. Website. http:www.monito.com/wankel/hydrogen.html.

(2) Rosen, M.A. and Scott D.S., 1986. Analysis and Comparison of the Thermodynamic Performance of Selected Hydrogen Production Processes. Can. Proc. Intersoc. Energy Convers. Eng. Conf., 21 ${ }^{\text {st }}$, vol. 1, pp. 266-271.

(3) Agnelli, M.E., Ponzi, E.N., and Yeramian, A.A., 1987. Catalytic Deactivation on Methane Steam Reforming Catalysts. 2. Kinetic Study. Ind Eng. Chem. Res. vol 26, pp. 1707-1713.

(4) Twigg, M.V. Catalyst Handbook pp.225-238. Wolfe Publishing Ltd., England 1989. 


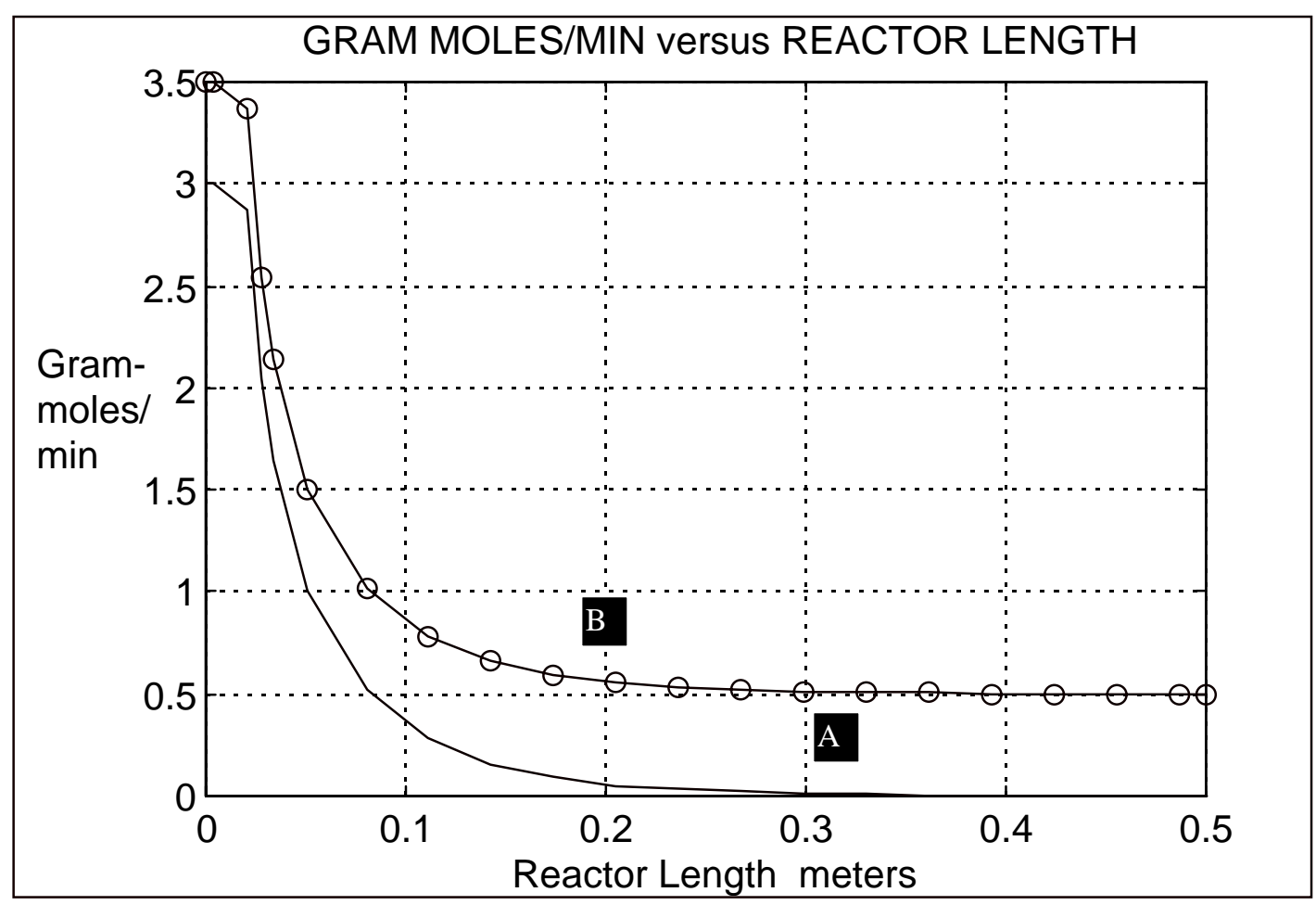

Figure 1: Ratio 3.5/3, $q=5000, S=.01$

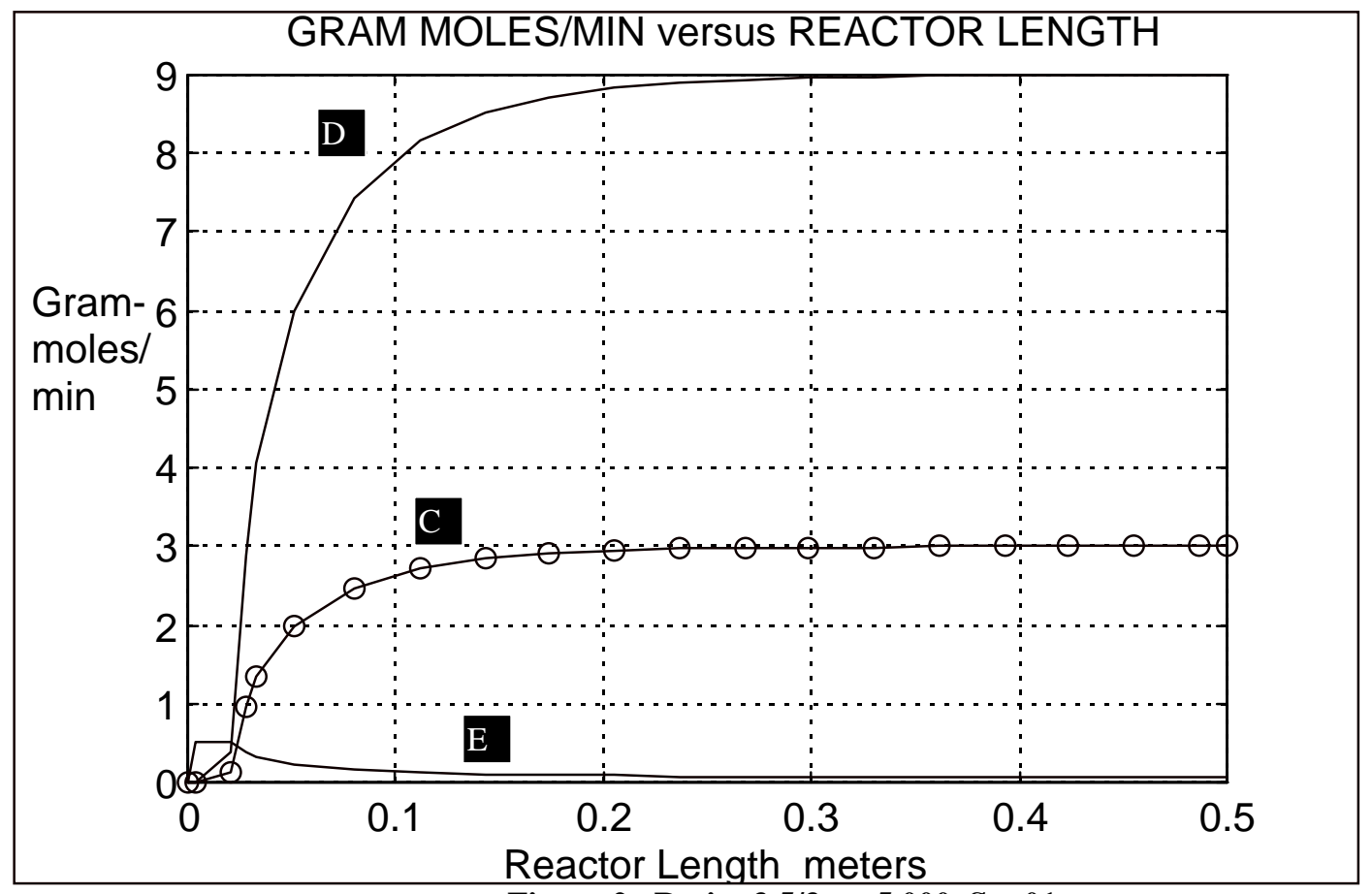

Figure 2. Ratio: 3.5/3, $q=5,000, S=.01$ 

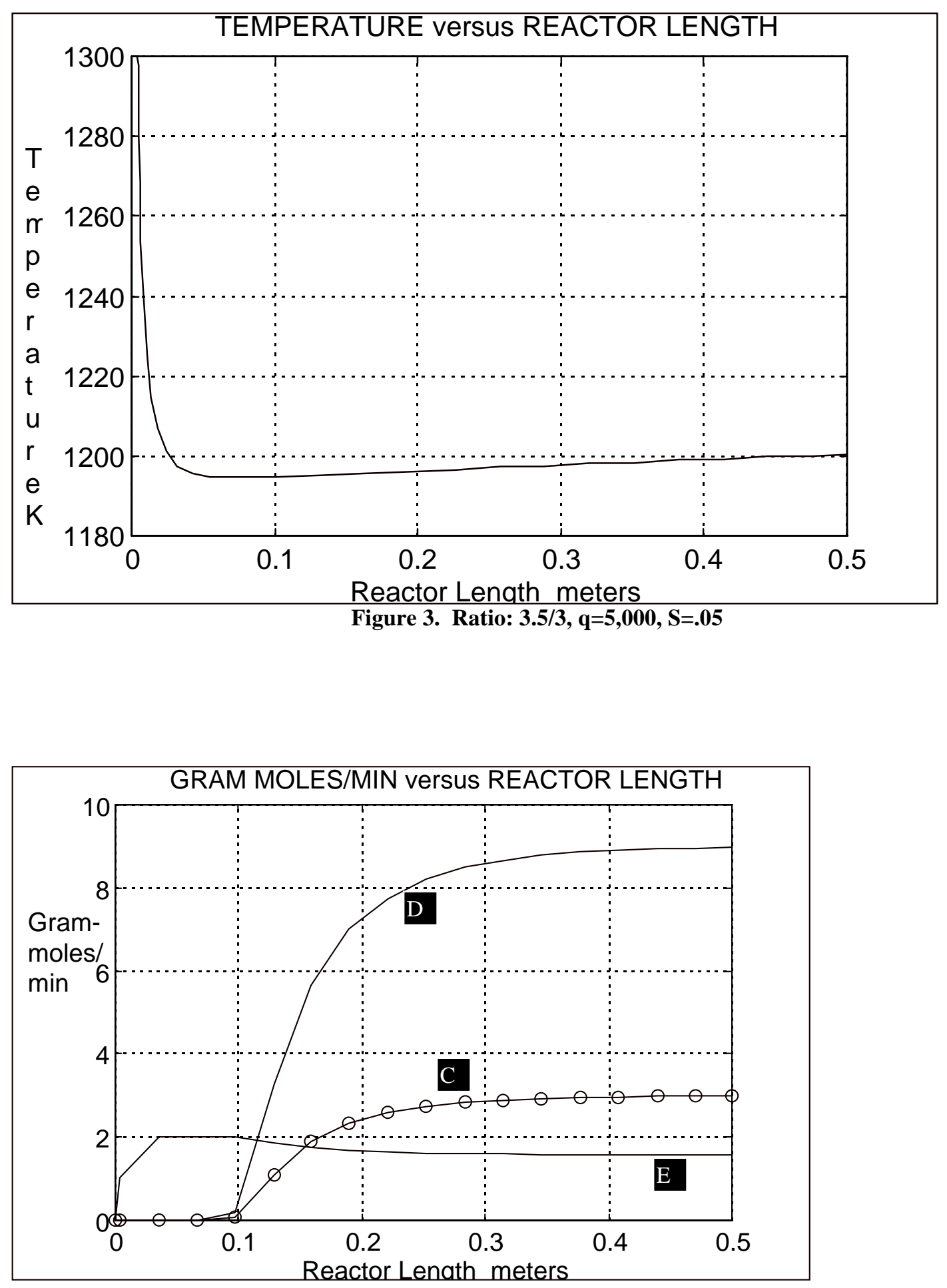

Figure 4. Ratio 13.5/3, $q=5000, S=0.05$ 


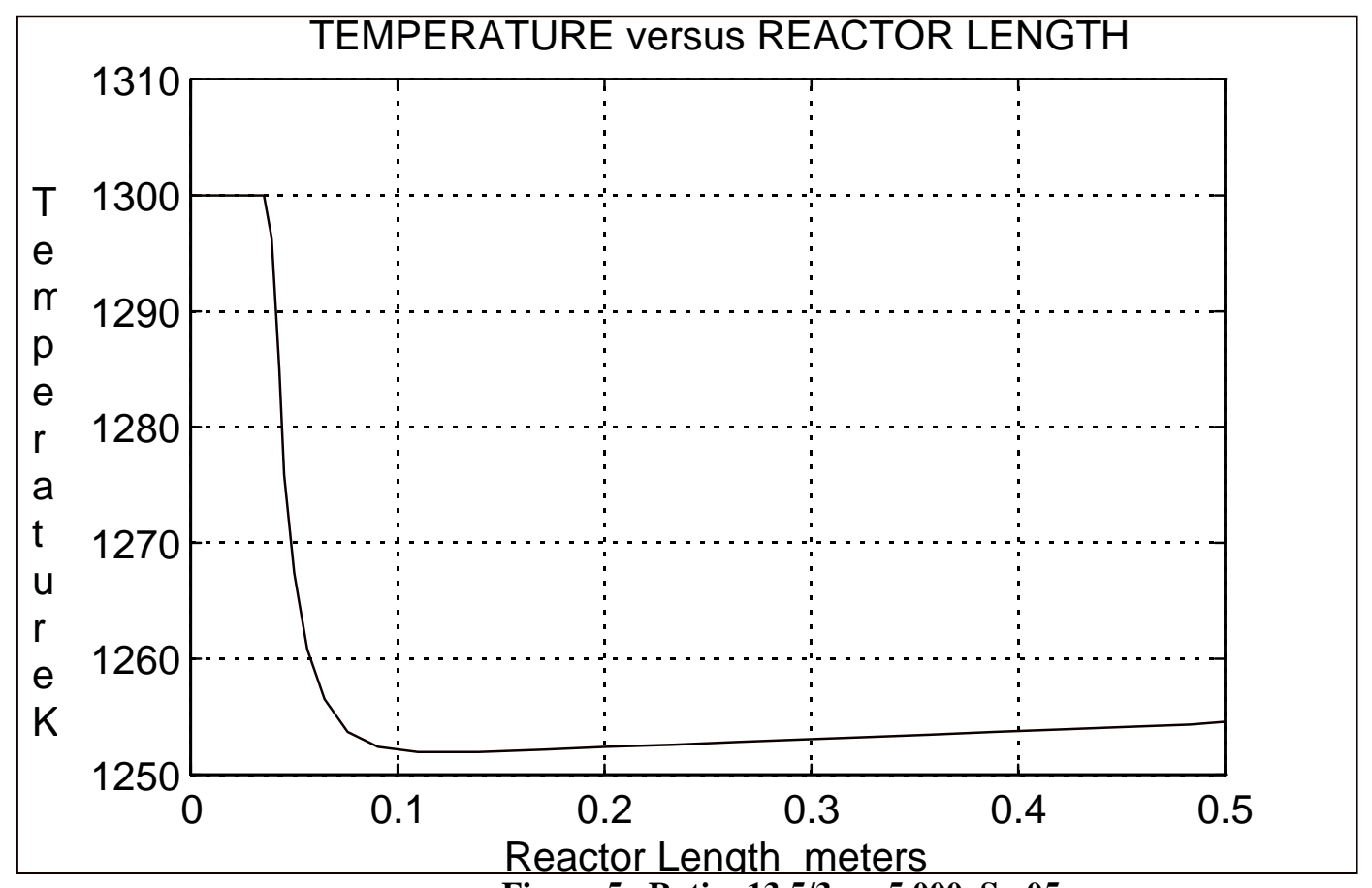

Figure 5. Ratio: 13.5/3, $q=5,000, S=.05$

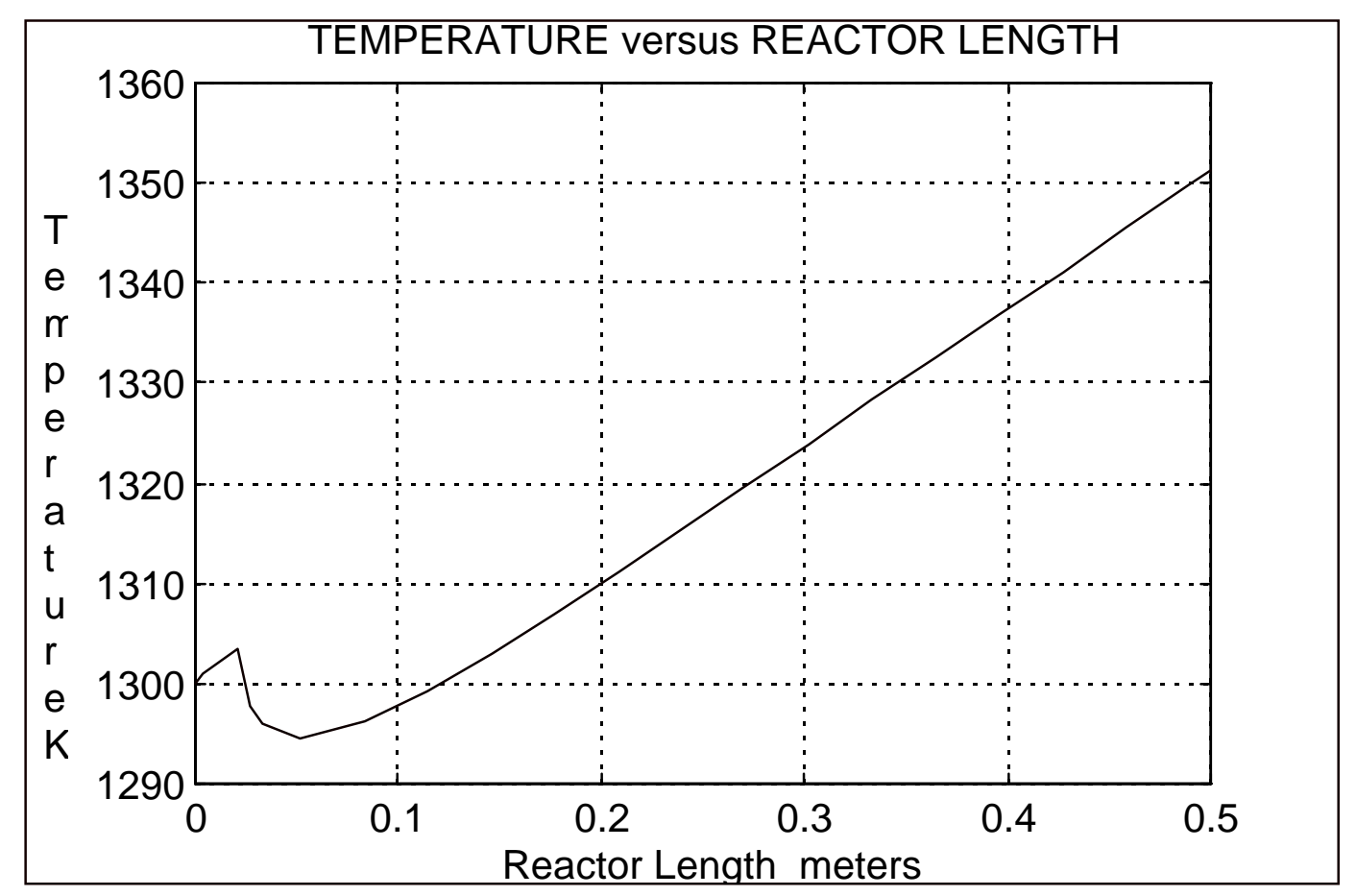

Figure 6. Ratio: 3.5/3, $q=50,000, S=0.01$

Charles U. Okonkwo 
Dr. Charles U. Okonkwo graduated with bachelors and masters degrees in chemical engineering from Iowa State University, and a Ph.D. in chemical engineering from the University of Florida. He has worked as a process engineer for both the chemical and semiconductor industries. Since joining the College of Technology and Applied Sciences at Arizona State University as a lecturer, he has taught graduate courses in hazardous waste management and undergraduate courses in the Department of Manufacturing. Prior to joining the College of Technology and Applied Sciences, he taught for several years in the Department of Mathematics at Arizona State University. 